\title{
MOTIVATIONAL FACTORS IN CONTINUING EDUCATION AN ACADEMIC ACHIEVEMENT OF ADULT LEARNERS
}

\author{
Pei Ling Lee \& Vincent Pang ${ }^{1}$ \\ Center for Academic Advancement \\ Universiti Malaysia Sabah \\ ${ }^{1}$ Correspondence author: pang@ums.gmail.com
}

\begin{abstract}
Purpose - The purpose of this study is to examine the relationship between motivational factors in continuing education and academic achievement of adult learners. The study is conducted due to a lack of research pertaining to academic achievement among adult learners particularly in Malaysia.
\end{abstract}

Methodology - A random sample of 150 part-time adult learners from a public university in Kota Kinabalu, Sabah, represented 202 part-time adult learners in the areas of social sciences and humanities at the university. A thirty-item questionnaire, adapted from Boshier's Education Participation Scale(EPS) (1991) and Neill's The University Students Motivation and Satisfaction Questionnaire 2 (TUSMSQ2) (2004) was used to examine their motivational factors i.e. personal development, career advancement, social pressure, social and communication improvement, and escapism. Self-reported cumulative grade point average (CGPA) was utilized as the measurement of academic achievement. Rasch analysis reaffirmed the content validity of items in the questionnaire.

Findings - The findings indicate that personal development and social pressure are the best predictors of academic achievement among adult learners. The motivational factors that are not significant as predictors are career advancement, social and communication improvement, and escapism. Adult learners with higher motivation for personal development (intrinsic motivation) perform better academically. Conversely, adult learners with higher 
motivation based on social pressure (extrinsic motivation) perform lower academically. Intrinsic motivation seems to be more powerful in enhancing academic achievement of adult learners as compared to extrinsic motivation.

Significance - This finding is crucial for program planners and adult educators. They will be able to lead adult learners to be more intrinsically motivated in continuing education. In this way, they will optimize their learning outcomes and develop quality human capital in Malaysia.

Keywords: Motivational factors, academic achievement, adult learners

\section{INTRODUCTION}

The growing number of adults returning to study in continuing education is a reality. Based on Chao, Stover DeRocco and Flynn (2007), adult learners aged 24 or older comprised of 44 percent of U.S. postsecondary students. In Malaysia, the number of parttime and open distance learning in Malaysian Public Institutions of Higher Education has increased significantly from 30,661 learners in 2002 to 49,309 learners in 2008 (Kementerian Pengajian Tinggi Malaysia, 2009).

Adults are motivated to participate in continuing education due to the demand of a globalized economy which emphasizes a knowledge-based society. Knowledge-based society accentuates the more highly-skilled and multi-skilled workers who have global mobility, highly competitive, productive, flexible, independent and critical thinkers (Tan, 2005). Therefore, working adults are aware of the fact and they engage in continuing education in order for them to survive better at workplace and to live better life (Madsen \& Wilson, 2006; Mulenga \& Liang, 2008).

Boshier (1991) state that adults are motivated by various internal or external factors to engage in continuing education (Garst \& Ried, 1999; Abdul Razaq Ahmad, Norshani Zainal Abiddin, Jamaludin Badusah \& Pang, 2009). However, Abdul Razaq Ahmad et al. (2009) 
revealed that eight percent of higher education institutions did not fulfill the needs of their learners through the offered programs and courses. Therefore, it is important for universities and institutions to better understand the issues of motivation among this growing population to know how to reach and teach them.

Besides, motivation is directly related to educational achievement (Wlodkowski, 1993). Various motivational factors of adult learners in continuing education may reflect their attitudes and perceptions in putting the necessary efforts in their study and thereby influence their academic achievement. According to Knowles, Holton, and Swanson (2011), there has been relatively little research pertaining to the issue on adult learning until lately. Specifically, most research on academic achievement is based on traditional young students, but very few empirical studies are available on non-traditional students, namely adult learners. On the other hand, there is a lack of research regarding the relationship between motivation in continuing education and academic achievement of adult learners (Miner, 1993; Storm, 1990).

Due to no major studies conducted with Malaysian workforce on the issue, this study is conducted to fill the gap. Understanding of motivational factors in influencing academic achievement of adult learners in their learning programs can assist government, the ministry of education, institutions of higher education, program planners and educators to better serve the needs of the learners. It also can enhance their academic success through the appropriate adjustment in policy, learning sources, administrative procedures, consultation services, educational programs, and quality of instruction (Abdul Razaq Ahmad et al., 2009; Storm, 1990).

\section{RESEARCH OBJECTIVES}

The major objective of this study is to examine the relationships between five motivational factors in continuing education with the academic achievement of part-time adult learners. The factors of adult learners are personal development, career advancement, social pressure, social and communication improvement, and escapism. This will help us determine the best predictors of academic achievement among adult learners. 


\section{LITERATURE REVIEW}

\section{Theoretical Framework}

Maslow's hierarchy of needs theory and Knowles' theory of andragogy were applied in this study. Maslow's hierarchy of needs theory was applied to identify motivational factors of adult learners to participate in continuing education based on their needs. Knowles' theory of andragogy was applied to identify characteristics and motivation of adults in learning in order to lead adult learners to their academic success.

According to Maslow's hierarchy of needs theory, human actions are directed towards satisfaction of their needs from the lower level needs to the higher level needs (Maslow, 1943). Needs are driving forces that arouse desires to acquire a change in behavior. A person seeks to meet successively higher needs which consist of physiological, safety, belongingness, self-esteem, and self-actualization. The advancement of one's needs to be the next level appears only when the present level need has been minimally fulfilled. In order to fulfill unsatisfied needs, adults are motivated to return to study (Abdul Razaq Ahmad et al., 2009). Maslow's humanistic view has been applied in business training to motivate employees to upgrade their educational levels in order for them to stay competitive in this knowledge-based society (Madsen \& Wilson, 2006).

Knowles' theory of andragogy was developed based on different characteristics and needs of adult learners (non-traditional students) as compared to traditional students. Andragogy puts emphasis on the accumulated life experiences of adult learners as their learning resources. The theory of andragogy proposes that adults have a need to know why they should learn and they want autonomy over what to learn (Knowles et al.,2011). Accordingly, adults are ready to learn the things that they need to know in order to cope effectively in real life situations. They apply what they have learned for application at their current workplace or to solve their life problems. Therefore, they are motivated to learn by some external factors. However, most of adults become more independent and intrinsically motivated to learn as they grow older (Knowles et al.,2011). 


\section{Motivational Factors in Continuing Education}

The new version of the Educational Participation Scale (EPS) (A-form) was developed by Boshier in 1991 to measure seven motivational factors of adult learners to advance their education. The seven factors are: communication improvements, social contact, educational preparation, professional advancement, family togetherness, escapism, and cognitive interest. According to Boshier (1991), adult learners are goal-oriented and motivated by either intrinsic or extrinsic forces to participate in continuing education.

Several studies, which utilized Boshier's EPS to measure motivational factors of adults in continuing education, found that the most influential motivational factors were cognitive interest and career advancement, whereas the least influential motivating factor was escapism (Raghavan \& Kumar, 2008; Joned \& Lee, 2006; Mulenga \& Liang, 2008; Garst \& Ried, 1999). Storm (1990) also revealed that the most influential motivational factors for adults to enroll in continuing education classes were cognitive interest and career advancement, but the least motivating factor was external expectations.

\section{The Relationship between Motivation in Learning and Academic Achievement}

Tan (2006) revealed that adult learners can be motivated to enjoy learning in order to lead them to succeed in their studies. Abdul Razaq Ahmad et al.(2009) found that positive motivation could lead adults to be self-directed, to learn more and obtain higher achievement in computer learning programs. Storm (1990) found that adult learners who ranked cognitive interest and career advancement with equal importance as the most influential motivational factors for them to participate in learning programs, were able to attain the highest grade point average (GPA) of 3.41. However, further analysis of regression findings indicated that social contact, escapism, career advancement, community service, external expectations, and cognitive interest did not contribute significantly to the prediction of academic achievement as measured by GPA among adult learners in Montana State University (MSU).

Hassan Afzal, Cheung, Imran Ali, Muhammad Aslam Khan and Kashif Hamid(2010) revealed that students who were intrinsically 
motivated by altruism and self-exploration to enter university obtained higher academic achievement. Conversely, students who were highly motivated by extrinsic factors of social pressure, social enjoyment, escapism, and career advancement performed lower academically. On the other hand, Bye, Pushkar and Conway (2007) found that adult learners with higher levels of intrinsic motivation would enjoy the educational process of mastering skills in learning. Miner (1993) found that adult students in Pennsylvania, seeking the nursing diploma, who had a higher level of intrinsic motivation were more successful in their studies. Bruinsma (2004) also revealed that students with higher intrinsic motivation were able to obtain deeper cognitive processing skills and performed better academically.

\section{METHODOLOGY}

This study was based on non-experimental quantitative research, utilizing the survey method. The motivational factors were tested for whether they were significant predictors for academic achievement of the learners through multiple linear regression.

The data were collected, keyed-in and analyzed by using Predictive Analytics Software (PASW) version 19 (formerly known as Statistical Package for the Social Sciences). PASW analyses were utilized to perform descriptive statistics, correlation and multiple regression analyses of variables.

\section{Sampling}

The population of the study is a total of 202 second and third year part-time adult learners who pursued undergraduate and postgraduate programs in the fields of social sciences and humanities in a public university in Kota Kinabalu, Malaysia. The programs were Bachelor of Psychology and Bachelor of Social Science; Master of Education in Curriculum and Instructional Design, TESL, Educational Management, and Computers-in-Education. A total of 150 samples (74.3\% of sample size) were selected using simple random sampling method. This number satisfies the minimum sample size requirement suggested by Krejcie and Morgan (1970). These learners met face-to-face with the researchers and answered questionnaire. The researchers clarified the questions on the spot whenever necessary. 


\section{Instrumentation}

The instrument is a 30-item questionnaire which was adapted from Boshier's EPS (1991) and Neills's (2004) University Student Motivation and Satisfaction Questionnaire version 2 (TUSMSQ2). The adaptation involved the merger of EPS and TUSMSQ2 in which the items were clustered to five motivational factors. The respondents were required to rate the five factors which influenced them to become involved in continuing education. Each item was rated on a five-point scale ( $1=$ no influence, $2=$ little influence, $3=$ moderate influence, $4=$ much influence, $5=$ very much influence). Respondents were also asked to state their latest cumulative grade point average (CGPA) in the same questionnaire.

Boshier's EPS was considered in the study due to its high reliability, clarity, validity, and applicability in measuring motivational factors of adults in continuing education (Joned \& Lee, 2006; Mulenga \& Liang, 2008). Meanwhile, TUSMSQ2 which created by Neill (2004), was used by Hassan Afzal et al. (2010) to investigate the relationships between motivational factors of students to continue their education with their academic achievement. Neill's TUSMSQ2 instrument consists of 30 items to measure sources of motivation including: self-exploration and altruism which are considered as intrinsic motivational factors, while rejection of alternative options, career and qualifications, social enjoyment, and social pressure which are considered as extrinsic motivational factors respectively. With the combination of comparable motivational factors and omission of a few of inappropriate motivational factors in Boshier's EPS and Neill's TUSMSQ2, the five finalized and constructed motivational factors to be measured in this study are personal development, career advancement, social pressure, social and communication improvement, and escapism. Personal development is categorized as intrinsic motivation, while the other four factors are categorized as extrinsic motivation. The five motivational factors are independent variables of study. Academic achievement, measured by cumulative grade point average (CGPA) of the learners, is the dependent variable of the study.

\section{Reliability and Validity of the Instrument}

Cronbach's Alpha coefficients were calculated for each factor to assess the reliability (internal consistency) of the resulting scales. 
From Table 1, it can be seen that all the reliability coefficients fall within the range from 0.77 to 0.91 . Considering the commonly minimal acceptable level for internal consistency of 0.60 (Sekaran, 2000), these values suggest that all scales measured by items in questionnaire generally have high reliability and can be utilized for further analysis.

Table 1

Cronbach's Alpha for the Scales of Motivational Factors in Continuing Education

\begin{tabular}{lcccc}
\hline \multirow{2}{*}{ Scale } & \multicolumn{4}{c}{$\mathrm{n}=150$} \\
\cline { 2 - 5 } & $\begin{array}{l}\text { Number } \\
\text { of Items }\end{array}$ & $\begin{array}{c}\text { Cronbach's } \\
\text { Alpha }\end{array}$ & Mean & $\begin{array}{c}\text { Std. } \\
\text { Dev }\end{array}$ \\
\hline Personal development & 6 & 0.80 & 3.95 & 0.71 \\
Career Advancement & 6 & 0.77 & 3.86 & 0.75 \\
Social Pressure & 6 & 0.82 & 3.20 & 0.97 \\
Social and Communication Improvement & 6 & 0.87 & 3.32 & 0.88 \\
Escapism & 6 & 0.89 & 2.38 & 1.04 \\
\hline
\end{tabular}

In order to further check the validity of items in questionnaire, validity testing was done through the observation of INFIT mean square values generated from Quest (Adams \&Khoo, 1996) analysis, which is a software based on Rasch model. It can be seen that all the values of INFIT mean square of all items as shown in Table 2 and the item map (Appendix) fall within the expected values of 0.60 to 1.40 , which are suggested by Bond and Fox (2001) as the acceptable indicators for fitting the Rasch model for rating scale test. These indicate that the data has a good fit to the model and the results support the validity of items in the questionnaire to measure the motivational factors of adult learners in continuing education through part-time learning programs.

\section{FINDINGS AND DISCUSSION}

\section{Socio-Demographic Profile}

Respondents were chosen from the areas of social sciences and humanities at a public university in Kota Kinabalu, Sabah. A majority 
of them are young adult learners, age of 30 or below (78.7\%). In terms of gender, findings indicate that female adult learners $(70.7 \%)$ dramatically outnumbered male adult learners (29.3\%). As for status, a majority of respondents $(75.3 \%)$ are still single, whereas $24.0 \%$ of the respondents are married and only one respondent is widowed. The distribution of respondents by prior educational level indicates that more than half $(61.3 \%)$ of respondents are STPM (equivalent to A-level) or diploma holders, whereas $38.7 \%$ of them possess bachelor degrees. The distribution of respondents by working experience indicates that most of the respondents $(70.7 \%)$ have four years of working experience or less, while $18.0 \%$ of them have five to ten years, and $11.3 \%$ of them have more than ten years of working experience.

Table 2

INFIT Mean Square Values of Items in Questionnaire $(\mathrm{N}=150, \mathrm{~L}=30$, Probability Level $=0.50)$

\begin{tabular}{cc}
\hline ITEM & INFIT Mean Square Value \\
\hline Item 1 & 1.16 \\
Item 2 & 1.37 \\
Item 3 & 0.94 \\
Item 4 & 1.04 \\
Item 5 & 1.16 \\
Item 6 & 1.05 \\
Item 7 & 1.06 \\
Item 8 & 1.08 \\
Item 9 & 0.89 \\
Item 10 & 1.03 \\
Item 11 & 0.90 \\
Item 12 & 1.08 \\
Item 13 & 0.86 \\
Item 14 & 1.03 \\
Item 15 & 0.95 \\
Item 16 & 1.00 \\
Item 17 & 1.00 \\
Item 18 & 1.19 \\
\hline
\end{tabular}




\begin{tabular}{cc}
\hline ITEM & INFIT Mean Square Value \\
\hline Item 19 & 0.90 \\
Item 20 & 0.87 \\
Item 21 22 & 0.90 \\
Item 22 & 0.82 \\
Item 23 & 0.85 \\
Item 24 & 0.98 \\
Item 25 & 0.84 \\
Item 26 & 0.79 \\
Item 27 & 0.89 \\
Item 28 & 0.94 \\
Item 29 & 0.96 \\
Item 30 & 1.12 \\
Mean & 0.99 \\
\hline
\end{tabular}

Table 3

Socio-Demographic Profiles of Part-Time Adult Learners

\begin{tabular}{|c|c|c|c|}
\hline \multirow{2}{*}{\multicolumn{2}{|c|}{ Demographic Variables }} & \multicolumn{2}{|c|}{ Total $(\mathrm{N}=150)$} \\
\hline & & F & $\%$ \\
\hline \multirow[t]{3}{*}{ Age } & 30 years old or below & 118 & 78.7 \\
\hline & $31-40$ years old & 22 & 14.7 \\
\hline & More than 40 years old & 10 & 6.6 \\
\hline \multirow[t]{2}{*}{ Gender } & Male & 44 & 29.3 \\
\hline & Female & 106 & 70.7 \\
\hline \multirow[t]{3}{*}{ Status } & Married & 36 & 24.0 \\
\hline & Single & 113 & 75.3 \\
\hline & Widowed & 1 & 0.7 \\
\hline \multirow{3}{*}{$\begin{array}{l}\text { Prior Education } \\
\text { Level }\end{array}$} & STPM/Diploma & 92 & 61.3 \\
\hline & Bachelor's Degree & 58 & 38.7 \\
\hline & 4 years or below & 106 & 70.7 \\
\hline \multirow{2}{*}{$\begin{array}{l}\text { Working Expe- } \\
\text { rience }\end{array}$} & $5-10$ years & 27 & 18.0 \\
\hline & More than 10 years & 17 & 11.3 \\
\hline
\end{tabular}

\section{Motivational Factors in Continuing Education among Part-time} Adult Learners

Table 4 shows the mean score of each item of the five motivational factors in continuing education among adult learners in enrolling part-time learning programs at the institution. Findings indicate 
that personal development ranked the highest mean score of 3.95 among all the five motivational factors for adults to embark on parttime learning. This finding is consistent with those of Mulenga and Liang (2008), Joned and Lee (2006), Garst and Ried (1999) and Storm (1990) who found the cognitive interest as the highest mean score of motivation in learning among adult learners. The mean scores of item 3 (to upgrade my knowledge and expand my mind) and item 4 (to improve my thinking skills) of 4.40 and 4.37 respectively are higher than other items in personal development, indicating that adult learners have strong internal motivation to learn for self-improvement particularly in terms of knowledge and thinking skills.

Next, career advancement ranked the second highest mean score of 3.86 as motivation for adults to return to study. Item 9 (to fit my future career plan) had the highest mean score of 4.41, as compared to other items in career advancement, indicating that adults engage in continuing education mainly to prepare themselves for future career development due to the growing demand for an educated workforce. Following career advancement, social and communication improvement had the mean score of 3.32, whereas social pressure had the mean score of 3.20 as motivation for adults to further study through the enrolment into part-time learning programs.

As expected, escapism ranked as the least (mean score $=2.38$ ) influential motivational factor for adults to seek out continuing education, which concurred with several previous studies (Raghavan \& Kumar, 2008; Joned \& Lee, 2006; Mulenga \& Liang, 2008; Garst $\&$ Ried, 1999). It can be seen that item 28 (to do something rather than nothing) shows the highest mean score (mean score $=2.78$ ) among all the items in escapism. Item 25 (to get a break from routine of home or work) has the second highest mean score in escapism (mean score $=2.42$ ) implying that adults consider continuing education as a way to temporarily keep apart from their daily workloads and burdens. Overall, it can be concluded that adults are highly motivated by personal development and career advancement in continuing education, followed by social and communication improvement, social pressure, and escapism. It shows that they are more motivated by intrinsic factor rather than extrinsic one, indicating their tendency to satisfy higher levels of needs of Maslow's (1943) hierarchy. 
Table 4

The Mean Scores of Motivational Factors in Continuing Education

\begin{tabular}{lcc}
\hline \multicolumn{1}{c}{ Items } & Mean & Std. Dev. \\
\hline Personal Development & & \\
1. To satisfy intellectual curiosity. & 3.90 & 1.07 \\
2. To seek knowledge for own sake. & 3.94 & 1.15 \\
3. To upgrade my knowledge and expand my mind. & 4.40 & 0.88 \\
4. To improve my thinking skills. & 4.37 & 0.85 \\
5. To learn just for the joy of learning. & 2.87 & 1.13 \\
6. To discover and realize my potential. & 4.19 & 0.87 \\
$\quad$ Personal Development Factor & $\mathbf{3 . 9 5}$ & $\mathbf{0 . 7 1}$ \\
\hline
\end{tabular}

\section{Career Advancement}

$\begin{array}{lll}\text { 7. To upgrade my knowledge and expand my mind. } & 4.00 & 1.06\end{array}$

$\begin{array}{lll}\text { 8. To help me get a higher pay job. } & 4.03 & 1.08\end{array}$

$\begin{array}{lll}\text { 9. To fit my future career plan. } & 4.41 & 0.83\end{array}$

10. To comply with my employer's policy. $\quad 2.83 \quad 1.33$

$\begin{array}{lll}\text { 11. To gain valuable skills for my career. } & 4.35 & 0.85\end{array}$

12. To fulfill my professional obligation. $\quad 3.55 \quad 1.33$

Career Advancement Factor $\quad 3.86 \quad 0.75$

\section{Social Pressure}

13. To keep up my academic qualifications on par with my $\quad 3.15 \quad 1.33$

family members, friends or colleagues.

$\begin{array}{lll}\text { 14. To prevail against others. } & 2.85 & 1.40\end{array}$

15. To be recognized and as good role-model for others. $\quad 3.77 \quad 1.18$

16. My family members, employer, friends or colleagues $3.87 \quad 1.19$

encourage me to further study to obtain higher level of education.

$\begin{array}{lll}\text { 17. Because others expect me to get a degree. } & 2.85 & 1.48\end{array}$

18. Because it would disappoint other people if I didn't. $\quad 2.68 \quad 1.43$

$\begin{array}{lll}\text { Social Pressure Factor } \quad 3.20 & 0.97\end{array}$

\section{Social and Communication Improvement}

19. To make new friends.

20. To meet different people.

$2.89 \quad 1.23$

21. To participate in more social activities.

$3.17 \quad 1.14$

22. To communicate better with others.

$3.82 \quad 1.04$

23. To enhance my skills for interpersonal relationship. $\quad 3.94 \quad 0.99$

24. To enjoy the social life and social environment. $\quad 3.45 \quad 1.14$

$\begin{array}{lll}\text { Social and Communication Improvement Factor } & 3.32 & 0.88\end{array}$ 


\begin{tabular}{lcc}
\hline \multicolumn{1}{c}{ Items } & Mean & Std. Dev. \\
\hline Escapism & & \\
25. To get a break from the routine of home or work. & 2.42 & 1.24 \\
26. To get away from loneliness. & 2.28 & 1.26 \\
27. To get relief from boredom. & 2.36 & 1.35 \\
28. To do something rather than nothing. & 2.78 & 1.36 \\
29. I have a lot of free time. & 2.25 & 1.27 \\
30. I don't have any better options. & 2.17 & 1.21 \\
Escapism Factor & $\mathbf{2 . 3 8}$ & $\mathbf{1 . 0 4}$ \\
\hline
\end{tabular}

\section{The Relationships between Motivational Factors and Academic Achievement}

Table 5 shows that only personal development as motivation to further study has positive relationship with academic achievement of adult learners in their part-time learning programs. Meanwhile, social pressure indicates negative and low relationship with academic achievement. The other three motivational factors do not correlate with academic achievement of adult learners. Adults who are motivated by personal development tend to obtain higher achievement in their learning. The explanation may be that they are intrinsically motivated and self-directed in continuing education for self-satisfaction. Therefore, they enjoy learning and endeavor to acquire deep understanding and mastery of skills in their learning programs. The finding concurs with the studies of Hassan Afzal et al. (2010), Bruinsma (2004) and Miner (1993), which found that students with higher level of intrinsic motivation in learning performed better academically.

Adult learners with a higher level of social pressure are found to perform lower academically. The finding is supported by Hassan Afzal et al. (2010), who revealed that extrinsically motivated students performed lower academically. This is probably that those who are motivated by external forces work to achieve their goals such as to live up with others and to conform to others' requirements only when the external forces are present. The interest in studying is not as sustainable as those who find the joy in learning and mastery of knowledge and skills. . 
Table 5

Pearson's Correlation, $r$ between Motivational Factors and Academic Achievement

\begin{tabular}{lccc}
\hline & $r$ & $\begin{array}{c}\text { Sig. } \\
\text { (2-tailed) }\end{array}$ & $\mathrm{N}$ \\
\cline { 2 - 4 } & \multicolumn{3}{c}{ Academic Achievement } \\
\hline Personal Development (Intrinsic Motivation) & $\mathbf{0 . 3 7}$ & 0.00 & 150 \\
Career Advancement (Extrinsic Motivation) & 0.02 & 0.81 & 150 \\
Social Pressure (Extrinsic Motivation) & $\mathbf{- 0 . 2 1}$ & 0.01 & 150 \\
Social and Communication Improvement(Extrinsic & 0.04 & 0.65 & 150 \\
Motivation) & & & \\
Escapism (Extrinsic Motivation) & -0.12 & 0.15 & 150 \\
\hline
\end{tabular}

\section{Five Motivational Factors in Predicting Academic Achievement}

Table 6 displays the result of stepwise multiple regression analysis in model 2 with the values of R-square of 0.22 . This means that motivational factors of adults in continuing education accounted for $22.0 \%$ of the variance in their academic achievement. The value of F-statistics (15.14) indicates that the data collected fit the model at significance level of 5 percent $(p<0.05)$. The regression model indicates that motivational factors are able to significantly influence the academic achievement of adult learners.

Table 6

Regression Analysis of Five Motivational Factors with Academic Achievement (Model Summary)

\begin{tabular}{cccccc}
\hline Model & R & R Square & Adjusted R Square & F & Sig. F Change \\
\hline $\mathbf{1}$ & 0.37 (a) & 0.14 & 0.13 & 23.46 & 0.00 \\
$\mathbf{2}$ & 0.47 (b) & $\mathbf{0 . 2 2}$ & 0.21 & 15.14 & 0.00 \\
\hline
\end{tabular}

a. Predictors: (Constant), Personal Development

b. Predictors: (Constant), Personal Development, Social Pressure

c. Dependent Variable: Academic Achievement

From Table 7, it can be seen that personal development contributes positively while social pressure contributes negatively to academic achievement of adult learners at 5 percent significance level $(p<$ 
$0.05)$. The other three variables are insignificant $(p>0.05)$, thus they are excluded from the regression equation. This suggests that for every one-unit increase in personal development, academic achievement increases by 0.24 . and for every one-unit increase in social pressure, academic achievement decreases by 0.12 . In short, only personal development and social pressure are the predictors for academic achievement of adult learners. The regression equation to predict academic achievement of part-time adult learners in CGPA is formed as shown below:

Academic Achievement $=2.61+(0.24 \times$ Personal

Development $)-(0.12 \times$ Social Pressure $)$

The findings of three insignificant motivational factors are consistent with the findings of Storm (1990). This implies that motivational factors of career advancement, social and communication improvement, and escapism do not contribute significantly to the academic achievement of adult learners. With regard to the finding of personal development, which is the intrinsic motivation, it is supported by several previous studies of Hassan Afzal et al. (2010), Bruinsma (2004) and Miner (1993). It is believed that intrinsic motivation could lead adults to enjoy educational process of mastering skills in learning (Bye et al., 2007) and achieve better academically as compared to extrinsic motivation. Accordingly, intrinsically motivated persons are truly interested in learning and in achieving high internal goals which resulting their overall consistent high performance academically.

Besides, the finding of social pressure as an extrinsic motivation is supported by study of Hassan Afzal et al. (2010). These kinds of students are only concerned with the attainment of milestones or the result of their studies such as acquiring a degree, keeping up with others, hoping to be recognized, and to complying with others' requirements. As discussed in the preceding section, this form of extrinsic motivation disappears when it is removed. It is less sustainable compared to intrinsic motivation in which students find joy in learning and acquiring skills. 
Table 7

Regression Analysis of Five Motivational Factors with Academic Achievement (Coefficients)

\begin{tabular}{clcccc}
\hline & & \multicolumn{2}{c}{$\begin{array}{c}\text { Unstandardized } \\
\text { Coefficients }\end{array}$} & \multicolumn{2}{c}{ Standardized Coefficients } \\
\cline { 3 - 6 } Model & \multicolumn{1}{c}{ Variables } & B & Beta & t-Value & Sig. \\
\hline \multirow{2}{*}{1} & (Constant) & 2.36 & & 13.85 & 0.00 \\
& Personal Development & 0.21 & 0.37 & 4.84 & 0.00 \\
2 & (Constant) & 2.61 & & 14.92 & 0.00 \\
& Personal Development & $\mathbf{0 . 2 4}$ & 0.43 & 5.72 & 0.00 \\
& Social Pressure & $\mathbf{- 0 . 1 2}$ & -0.29 & -3.89 & 0.00 \\
\hline
\end{tabular}

Dependent Variable: Academic Achievement

\section{CONCLUSION AND RECOMMENDATION}

It is recommended that similar studies to be conducted in future to involve larger population and sample size. The low variance explained in model of this study implies that academic achievement of adult learners may be influenced by other variables such as selfefficacy, barriers, and learning strategies. Hence, these variables can be included in future similar studies in order to better predict academic achievement of adult learners. Besides, most of the respondents involved in this study are young adult workers instead of mid-career workers. This issue can be further investigated in future studies.

However, this study was important in that it found that adults have different motivational factors in continuing education through parttime learning programs. This is consistent with Knowles' theory of andragogy which claims that adults are motivated to learn by some intrinsic and extrinsic factors. In Maslow's (1943) hierarchy of needs, the extrinsic factors are lower and the intrinsic ones are higher in the order. In accordance with the globalized economy which put emphasis on educated workforce with higher levels of skills and credentials, adults are highly motivated to further study in order to fulfill their unsatisfied needs particularly for personal development and career advancement (Madsen \& Wilson, 2006; Maslow, 1943). They intend to pursue further learning in order to 
enrich their knowledge and thinking skills, to fit into future career plan, and to gain valuable skills to apply in their real life situations particularly in their workplace (Knowles et al., 2011). The findings are also in consistent with previous studies of Storm (1990), Garst and Ried (1999), Joned and Lee (2006), and Raghavan and Kumar (2008), which found that personal development and career advancement were the prevalent motivational factors for adults to involve in learning.

Furthermore, this study found that academic achievement increases with personal development (intrinsic motivation), but decreases with social pressure (extrinsic motivation). Among the five motivational factors involved in this study, only personal development and social pressure are the best predictors of academic achievement. In brief, adult learners with higher intrinsic motivation of personal development and lower extrinsic motivation of social pressure would obtain higher academic achievement. The finding that career advancement, social and communication improvement, and escapism are not predictors for academic achievement provides opportunities for future studies, especially with qualitative approach.

Intrinsic motivation seems to be more powerful as compared to extrinsic motivation in enhancing academic achievement of adult learners. The findings are supported by Hassan Afzal et al. (2010), who found that students with higher intrinsic motivation associated with lower extrinsic motivation achieved better academically. The reason could be intrinsically motivated learners would enjoy whole learning process; therefore they put more in effort. In turn, this could lead them to obtain deeper cognitive processing skills and ultimately to achieve academic success (Bye et al., 2007; Bruinsma, 2004).

Understanding of motivational factors in continuing education among adult learners is crucial for the Malaysian Ministry of Higher Education and institutions of higher education to facilitate the fulfillment of needs in terms of personal development and career advancement through the appropriate planning and design of adult education programs. This is helpful particularly in attracting more working adults to participate in continuing education in order to create a knowledge-based society in Malaysia. Besides, the study of motivational factors as predictors for academic achievement in adult education is important because such major studies have not been conducted with Malaysian workforce. 
The results of this study also suggest that program planners and adult educators should assist adult learners to be more intrinsically motivated in continuing education. To achieve this, administrators of higher education and program planners need to figure out the barriers of adult learners in learning, thereby arranging and organizing appropriate workshops, seminars, and consultation services which can enable them to overcome their barriers, and at the same time enhancing their affection towards knowledge and interests in learning (Tan, 2006). Meanwhile, adult educators can apply Knowles' and pedagogical approach in the teaching and learning process to create an enjoyable learning environment for adult learners in order to optimize their learning outcomes, thus to lead them to academic success (Tan, 2006; Knowles et al., 2011). In a broader scope, all stakeholders in higher education need to be exposed, reoriented, and reeducated on their mindset about the creation and provision of motivation for adult learners. They should be made to understand that only studies driven by the learners themselves are sustainable and thus are associated with higher achievement. This means that, for example, it is more effective for higher education institutions to affirm the efforts and success of adult learners rather than to provide materialistic incentives or instate peer pressures.

\section{REFERENCES}

Abdul Razaq Ahmad, Norhasni Zainal Abiddin, Jamaludin Badusah \& Pang, S. W. (2009).Computer usage and achievement among adults in rural area Malaysia. Journal of Social Sciences, 5(1), 1-8.

Adam, R. J., \& Khoo, S. T. (1996).Quest: The interactive test analysis system. Melbourne, Australia: Australia Council for Educational Research.

Bond, T. G., \& Fox, C. M.(2001). Applying the Rasch Model: Fundamental measurement in the human sciences. NJ: Lawrence Erlbaum Associates.

Boshier, R. (1991). Psychometric properties of the alternative form of the educational participation scale. Adult Education Participation Quarterly, 41(3), 150-167.

Bruinsma, M. (2004). Motivation, cognitive processing and achievement in higher education. Learning and Instruction, $14,549-568$. 
Bye, D., Pushkar, D. \& Conway, M. (2007). Motivation, interest, and positive affect in traditional and non-traditional undergraduate students. Adult Education Quarterly, 57(2), 141-158.

Chao, E. L., Stover DeRocco, E. \& Flynn, M. K. (2007). Adult learners in higher education: Barriers to success and strategies to improve results, Employment and Training Administration Occasional Paper 2007-03. Washington, DC.

Garst, W. C., \& Ried, L. D. (1999). Motivational orientations: Evaluation of the education participation scale in a Nontraditional Doctor of Pharmacy Program. American Journal of Pharmaceutical Education, 63,300-304.

Hassan Afzal, Cheung, S. W., Imran Ali, Muhammad Aslam Khan \& Kashif Hamid. (2010). A study of students' motivation and its relationship with their academic performance. International Journal of Business and Management, 5(4), 80-89.

Joned, R.,\& Lee, L. H.(2006). Motivational Orientations of Teachers in the National Professional Qualification for Headship (NPQH) Programme. Pertanika J. Soc. \& Hum, 14(2), 85-94.

Kementerian Pengajian Tinggi,(2009). Laporan statistic pelajar, Malaysia. Kementerian Pengajian Tinggi. Retrieved from http://www.mohe.gov.my/web_statistik

Knowles, M. S., Holton, E. F., \& Swanson, R. A. (2011).The adult learner: The definitive classic in adult education and human resource development (7th ed.).USA: Elsevier.

Krejcie, R.V. \& Morgan, D.W. (1970). Determined sample size for research activities. Educational and Psychological Measurement, 30 (3): 607-610.

Maslow, A. H. (1943). A theory of human motivation. Psychological Review, 50(4), 370-396.

Madsen, S. R.,\& Wilson, I. (2006). The influence of Maslow's humanistic views on an employee's motivation to learn. Paper presented at the Mountain Plains Management Conference. Orem, Utah.

Miner, M. B. (1993). Relationship of intrinsic motivation and academic achievement among adult diploma nursing students. Duquesne University.

Mulenga, D., \& Liang JR, S. (2008), Motivations for older adults' participation in distance education: A study at the National Open University of Taiwan. International Journal of Lifelong Education, 27(3), 289-314.

Neill, J. (2004).The university student motivation and satisfaction questionnaire version 2. Centre for Applied Psychology, University of Canberra. 
Raghavan S.,\& Kumar P. R. (2008). The need for participation in open and distance education: The Open University Malaysia experience. Turkish Online Journal of Distance EducationTOJDE, 9(4), 77-88.

Sekaran, U.(2000).Research method for business: A skill building approach. John Wiley, New York.

Storm, B. A. (1990). A study of the relationship between perception and judgment, locus of control, motivation to enroll, and academic achievement of nontraditional university students (Unpublished doctoral dissertation). Montana State University.

Tan, H. L. (2006). Motivation and task difficulty: A solo experience with adult learners. Jurnal Pendidikan, 31, 71-81.

Tan, P. L.(2005). Approaches to learning and learning values: An investigation of adult learners in Malaysia (Unpublished doctoral dissertation).Queensland University of Technology.

Wlodkowski, R. (1993). Enhancing adult motivation to learn: A guide to improving instruction and increasing learner achievement. San Francisco: Jossey-Bass. 


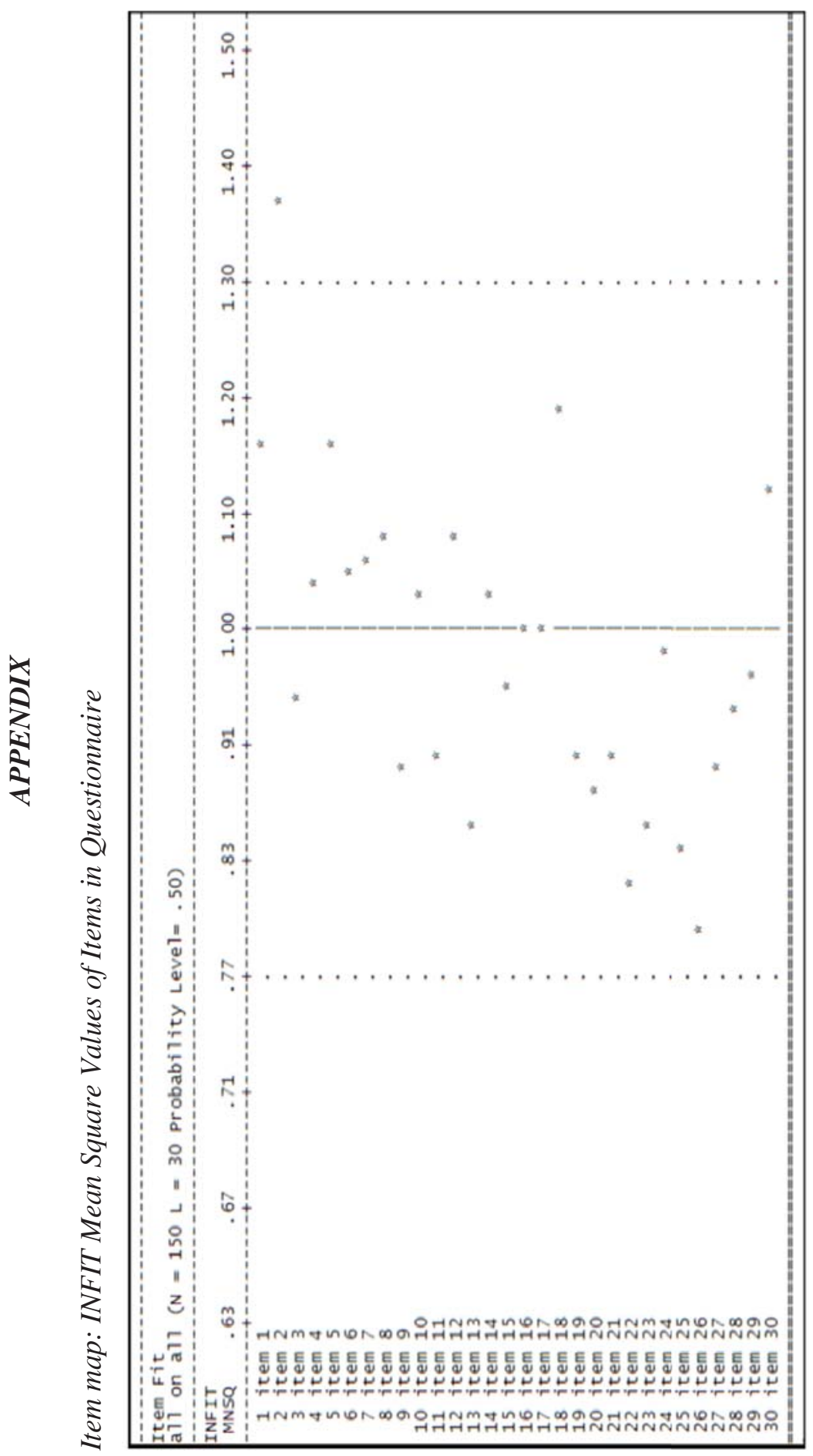


